\title{
The Possible Protective Effects of Coenzyme Q10 on Malathion-induced Testicular Toxicity in Male Rats

\author{
Marwa Medhet ${ }^{*}$
}

\begin{abstract}
Background: The organophosphorus (OPP) pesticide malathion (MAL) is ubiquitous in our environment causing multiorgan dysfunction including reproductive impairments. Objectives: To investigate the possible protective effect of coenzyme-Q10 (CoQ10) on malathion induced testicular toxicity. Materials and methods: This study employed four experimental groups ( $n=$ 8) each that underwent 30 days of treatment as follows: the control, CoQ10 group (10 $\mathrm{mg} / \mathrm{kg} /$ day, orally), MAL group (27 mg/kg/day, orally), and CoQ10+MAL group. At the end of the experiment, rats were sacrificed, dissected, and testis tissue samples were obtained and sperm motility and antioxidant parameters were examined. Tissue samples were also histopathologicaly and immunohistochemically assessed. Samples of blood were collected for assessing the levels of serum hormones, namely follicle-stimulating hormone (FSH), luteinizing hormone (LH) and testosterone. Results: MAL exposure affects sperm parameters (motility, count), testes and body weight. Moreover, MAL caused a decrease in serum testosterone and LH levels and increase FSH level. Additionally, exposure to MAL resulted in significant oxidative damage to the testes tissues. MAL raised the levels of pro-oxidant MDA and reduced the amount of antioxidant enzymes (SOD and GSH). Further, MAL treatment induced apoptosis in the testicular cells, as indicated by an increase in Bax and caspase 3 expressions. Conclusion: It was concluded that CoQ10 represents a potential protective option to protect the testicular tissue from the reproductive impairments associated with exposure to MAL.

Keywords: Malathion, Testicular Toxicity, Coenzyme-Q10, Oxidative stress, Apoptosis.
\end{abstract}

\section{Introduction.}

The environment is increasingly being influenced by the presence of waste and sub products of natural and anthropogenic origin. Anthropogenic pollution is evidenced in a large number of chemicals, such as drugs, food additives or pesticides, which would be largely responsible for damage and alterations at

\footnotetext{
${ }^{*}$ Lecturer, Crime Investigation Res Dep., Chemical and Biological Res. Division, National Center for Social and Criminological Research.
}

The National Review of Criminal Sciences, Volume 64, No. 2, July 2021. 
morphological and genetic levels in several species ${ }^{(1,2)}$. Although these chemicals are useful in some aspects (industrial and agricultural), their inappropriate application can induce health problems which includes carcinogenicity, reproductive toxicity, neurodegenerative diseases and disruption of endocrine system. In this respect, efficient strategies should be applied to reduce pesticide residue in food stuff $f^{(3,4)}$.

Exposure to harmful environmental agents affects human reproductive capacity $^{(5)}$. Many chemical and physical agents that were designed for industrial and agricultural purposes have led to a rise in male reproductive problems, such as infertility, sexual dysfunction, cryptorchidism, hypospadias, and testicular cancer $^{(6,7)}$. Testicular dysfunction is a chronic disorder of unclear etiology, characterized by the destruction of the germ cells of seminiferous tubules in addition to other supplementary cells such as Sertoli cells and Leydig cells ${ }^{(8)}$.

Organophosphorus pesticide (OPPs) is a class of pesticides has a toxic effect which considered a major global health problem. Malathion (MAL) is a widely used OPP is of relatively low acute toxicity compared to other OPPs, which makes it widely used in agricultural pest control ${ }^{(9)}$. However, widespread of its use may lead to excessive exposure from multiple sources including air, water, or food that leads to MAL toxicity. Exposure to MAL has been associated with different toxicities that nearly affect every single organ in our bodies as liver, kidney, testes, ovaries, lung, pancreas, and blood ${ }^{(10)}$. Moreover, MAL has adverse effects on testicular functions, thereby reducing male reproductive fitness, interfering with male fertility and sexual development, and impairing the quality of life ${ }^{(11)}$. Several studies reported that MAL induced testicular damage through several mechanisms: first, because of its lipophilic feature which in turn facilitates its diffusion with subsequent accumulation of acetylcholine in the target organ ${ }^{(12)}$. Bayrami et al. 2012 reported oxidative stress damage in different tissues with the generation of reactive oxygen species (ROS) is another way of organ damage by $\mathrm{MAL}^{(13)}$. Moreover, degenerative changes, necrosis, apoptosis and edema in the interstitial tissues and seminiferous tubules were reported as a result of MAL toxicity ${ }^{(14,15)}$.

Oxidative stress might be relieved by using antioxidant therapy. Recently, there is a major inclination toward the utilization of natural products as antioxidant agents. Coenzyme Q10 (CoQ10), also known as ubiquinone, is a 
naturally occurring endogenous energy promoting antioxidant concentrated in the mitochondria of eukaryotic cells, where it functions as a key element in the electron transport chain and thus an important factor in energy production with documented antioxidant and anti-inflammatory characters ${ }^{(16,17)}$. In addition, CoQ10 is able to prevent lipid peroxidation and adjust cytoplasmic redox potentials ${ }^{(18)}$, so it has been used as an attractive intervention approach in both treatment and prevention of a wide-range of pathological diseases or disorders in the last decade. Moreover CoQ10 is present endogenously in seminal fluid; improving sperm function ${ }^{(19)}$ enhancing several key features of semen on the other hand, impaired sperm parameters were recorded as a result of deficiency in CoQ10 level ${ }^{(20,21)}$.

The aim of the present study was to investigate the possible protective effects of CoQ10 against MAL-induced testicular damage and the induced reproductive toxicity in male rats.

\section{2- Materials and Methods}

\subsection{Drugs and chemicals:}

a) Malathion: High technical grade (98\% purity), was purchased from the branch of the Ministry of Agriculture, Egypt.

b) CoQ10 was sourced from Sigma-Aldrich (St. Louis, MO, USA). CoQ10 powder was dissolved in saline solution $(0.9 \% \mathrm{NaCl})$ containing $1 \%$ Tween 80 $(v: v)$ by stirring overnight at $25^{\circ} \mathrm{C}$.

c) Kits for assaying MDA, malondialdehyde; SOD, superoxide dismutase; $\mathrm{GSH}$, glutathione; LH, luteinizing hormone; and $\mathrm{FSH}$, follicle-stimulating hormone; and testosterone were purchased from Sigma Chemical Company (St. Luis, MO, USA). All the utilized solvents in this research were of high grade and were purchased from Sigma Chemical Company (St. Luis, MO, USA).

d) Primary antibodies for caspase 3 (cat \# PA1-29157) and Bax (cat \# PA511378) were got from Thermo Fisher Scientific Company Fremont, USA 


\subsection{Animals and Experimental Design}

Thirty two Adult male Wistar rats of 170-220 g weight were obtained from the Nile Co. for Pharmaceuticals and Chemical Industries, Cairo, Egypt. Rats were $10-12$ weeks old, which is equivalent to young adult age in humans ${ }^{(22)}$.

The rats were maintained under controlled temperature and 12 hours light/12 hours dark conditions for one week before the start of the experiments. They were allowed ad libitum access to standard laboratory feed and tap water. The study was conducted in the Laboratory of Animals Research Center in the Faculty of Medicine, Ain Shams University. Before the start of experiments, animals were left to acclimatize for one week ,then, were divided into four groups: (1) control $(\mathrm{n}=8)$ received corn oil $(0.5 \mathrm{ml} / \mathrm{kg}$ via gastric gavage) daily as vehicle for malathion, and saline $(10 \mathrm{ml} / \mathrm{kg}$ via gastric gavage) daily as vehicle for CoQ10, (2) CoQ10-treated group $(\mathrm{n}=8)$ : receiving single daily oral dose of $10 \mathrm{mg} / \mathrm{kg} /$ day CoQ10 via gastric gavage ${ }^{(23)}$ (3) MAL-treated group $(\mathrm{n}=8)$ : receiving $27 \mathrm{mg} / \mathrm{kg}$ in corn oil $0.5 \mathrm{ml} / \mathrm{kg}$ via gastric gavage) daily ${ }^{(24)}$; (4) MAL/CoQ10-treated group $(n=8)$ receiving both MAL and CoQ10 at previously indicated dosage and time. Throughout the experiment (30 days), all animals were observed at least once a day, which is in line with euthanasia guidelines for clinical signs of toxicity related to MAL exposure

\subsection{Physiological assessment}

Body weights of rats were recorded weekly during the study. After the animals were sacrificed; after 30 days, both testes were collected and weighed.

\subsection{Sampling and Tissue Preparations}

At 24 hours after the last dose, Blood samples were collected, left for $60 \mathrm{~min}$ to clot and then centrifuged for $10 \mathrm{~min}$ at $2430 \times \mathrm{g}$. The obtained clear sera were stored at $-80^{\circ} \mathrm{C}$, then rats were sacrificed by cervical dislocation

Both testes were rapidly excised and weighed. Right testis was processed for histopathology and immunohistochemistry studies (Samples in $10 \%$ Formaldhyde). The left testes was snap-frozen in liquid nitrogen and kept at $-80{ }^{\circ} \mathrm{C}$. For biochemical analysis, testes were homogenized and a $20 \%(\mathrm{w} / \mathrm{v})$ homogenate was prepared in ice-cold phosphate buffer $(0.01 \mathrm{M}, \mathrm{pH} 7.4)$. The homogenate was spinned at $3000 \mathrm{rpm}$ for $20 \mathrm{~min}$ and homogenate supernatant 
was then divided over several containers to avoid sample thawing and refreezing, and was kept at $-80^{\circ} \mathrm{C}$ till used.

\subsection{Sperm collection and evaluation}

Sperm were obtained by mincing epididymidis and the caudal epididymis in 5 $\mathrm{mL}$ of warm $\left(37^{\circ} \mathrm{C}\right)$ phosphate buffered saline PBS $\mathrm{pH} 7.4$, then tissue homogenates were performed at $100 \mathrm{rpm}$ for 30 seconds. Sperm counts and motility was measured in terms of the percentage of motile spermatozoa in total spermatozoa using a hemocytometer under a light microscope and expressed as million/ml. ${ }^{(25)}$.

\subsection{Biochemical analysis of testicular tissue homogenate}

Assessment of testicular antioxidant defense mechanisms was done in tissue homogenates, evaluating GSH concentration, lipid peroxide content, and SOD activity. For GSH, a spectrophotometric kit was used. In Brief, the method is based on the basis that the sulfhydrylcomponent of GSH reacts with 5,5 dithio-bis-2-nitrobenzoic acid (Ellman's reagent) producing 5-thio-2nitrobenzoic acid having a yellow color, that was measured colorimetrically at $405 \mathrm{~nm}$ (Beckman DU-64 UV/VIS spectrophotometer). SOD determination method is based on the production of superoxide anions by pyrogallol autoxidation to produce nitro blue tetrazolium (NBT) formazan color; the amount of produced superoxide anions scavenged by SOD was measured colorimetrically using spectrophotometer at $560 \mathrm{~nm}$. The testicular content of lipid peroxides was determined by biochemical assessment of thiobarbituric acid reacting substance through spectrophotometric measurement of color at $535 \mathrm{~nm}$, using1,1,3,3-tetramethoxypropane as standard.

\subsection{Histopathological and immunohistochemical examination}

Testes were fixed in $10 \%$ formalin then embedded in paraffin were sectioned by a microtome at $5 \mu \mathrm{m}$ thickness and stained with hematoxylin and eosin for routine histopathological assessment. Immunohistochemical staining was performed according to Côté A.,et $\mathrm{al}^{(26)}$. For quantitative analysis of immunohistochemical staining of caspase 3 and BAX, Immunostaining reaction was quantified using Leica Qwin 500 image analyzer computer system (London, UK) and their percentage of total number of cells is calculated in five 
fields/section of each of three slides from each animal group ${ }^{(27)}$, using light microscopy (Olympus CX41).

\subsection{Statistical analysis:}

Data were analyzed using a one-way ANOVA followed by Tukey (Prism 8, $\mathrm{GraphPad})$. All results are presented as the means $\pm \mathrm{SD}$. The differences were considered significant when the calculated $\mathrm{P}$ value was less than $0.05(\mathrm{P}<$ $0.05)$.

\section{Results}

\subsection{Effect of CoQ10 on total body weight, testes weight and Sperm} Parameters in MAL-treated rats

Rats treated with MAL at a dose of $27 \mathrm{mg} / \mathrm{kg}$ for 30 days showed clinical signs of toxicity expressed as decreased both testes and body weights. There was no significant difference in body weight between the different groups at the beginning of the experiment, However, on day 30, the absolute testicular weight of the MAL-group decreased significantly compared to the control group $(\mathrm{P}<0.05) \quad($ Table 1). Compared with the MAL-group, CoQ10 administration for 30 days significantly increased the absolute testicular weight $(\mathrm{P}<0.05)$.

MAL-treated rats revealed decreased sperm motility and count compared to the control group. There was no significant difference between CoQ10 - treated rats and the control group where the sperm motility and count of MAL-treated rats were significantly lower than that in the CoQ10/MAL-treated group. (Table 1) 
Table (1): Effect of CoQ10 on total body and testes weight and sperm motility and count in rats exposed to MAL-treated rats at day 30.

\begin{tabular}{|c|c|c|c|c|}
\hline Parameters & Control & CoQ 10 & MAL & MAL+CoQ 10 \\
\hline Body Weight & $3.034 \pm 0.117$ & $3.113 \pm 0.155$ & $2.280 \pm 0.128^{\mathrm{a}}$ & $2.750 \pm 0.129^{b}$ \\
\hline Testes Weight & $187.0 \pm 9.055$ & $190.8 \pm 5.560$ & $169.3 \pm 2.986^{\mathrm{a}}$ & $184.3 \pm 3.862^{a, b}$ \\
\hline Sperm motility & $87.25 \pm 4.573$ & $87.20 \pm 5.357$ & $48.50 \pm 1.291^{\mathrm{a}}$ & $77.50 \pm 4.796^{\mathrm{a}, \mathrm{b}}$ \\
\hline Sperm count & $69.50 \pm 4.203$ & $68.00 \pm 2.160$ & $29.50 \pm 2.646^{a, b}$ & $52.50 \pm 3.873^{\mathrm{a}, \mathrm{b}}$ \\
\hline
\end{tabular}

- Values are represented as means $\pm \operatorname{SD}$. $(n=6)$.

- a Denotes significance of different groups vs. Control group: $\mathrm{P}<0.05$.

- ${ }^{\mathrm{b}}$ Denotes significance of different groups vs Lead intoxicated group: $\mathrm{P}<0.05$

3.2. Effect of CoQ10 on Serum Levels of Testosterone, LH and FSH in MAL-treated rats at day 30

Rats received MAL only without coenzyme Q10 treatment showed a significant reduction in serum testosterone and LH levels as compared to the control group and the serum FSH levels were significantly increased. However Coadministration of CoQ10 with MAL in group 4 improves the serum levels of these hormones and regains them to near control group levels $(p<0.05)$. Nonsignificant difference was found in all the parameters between the control group and CoQ10 group ( $\mathrm{p}>0.05)$. 


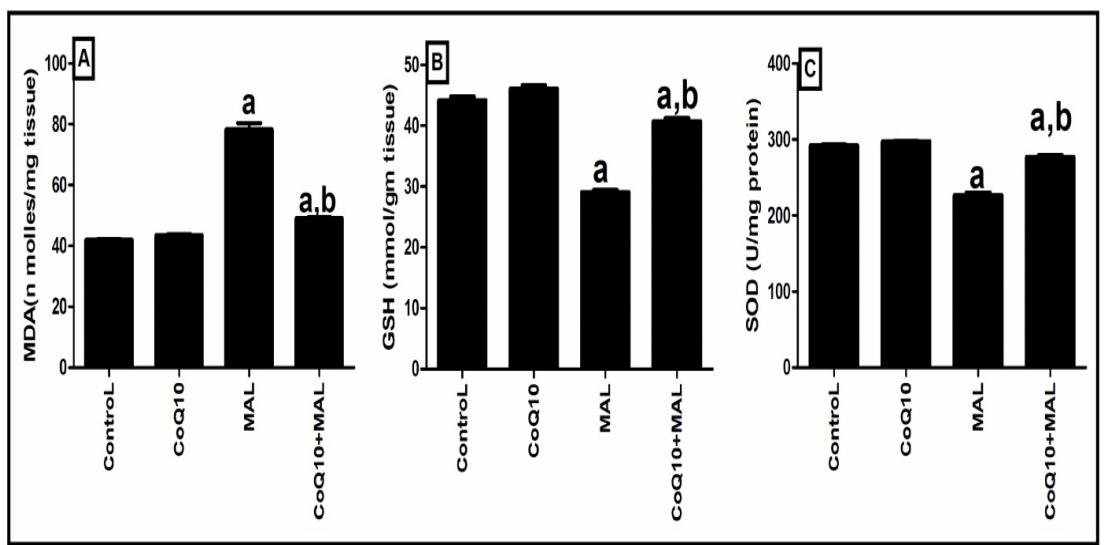

Fig.1: Effect of coenzyme (CoQ10, $10 \mathrm{mg} / \mathrm{kg})$ administration on the plasma levels of testosterone (A), FSH (B), and LH (C) in rats exposed to Malathion (MAL $27 \mathrm{mg} / \mathrm{kg}$ ) induced toxicity. Values are represented as means $\pm S D$. $(n=6)$. Significant difference is reported when $P<0.05$. $^{a}$ Significant difference compared to control, ${ }^{b}$ significant difference compared to MAL.

\subsection{Effects of CoQ10 on testicular oxidative stress markers in MAL-} treated rats at day 30

MAL impaired the balance between pro- and antioxidants in the testicular tissues as demonstrated by increased glutathione depletion $(p<0: 05)$ observed in MAL-treated rats. Moreover, we were able to demonstrate a significant decrease in the activity and expression of the antioxidant enzyme SOD with increase in MDA tissue concentation in MAL treated rats when compared to the control group. As expected, Concomitant treatment with CoQ10 and MAL significantly restored testicular GSH concentration and SOD activity whereas the levels of MDA were decreased compared to MAL-treated group. 


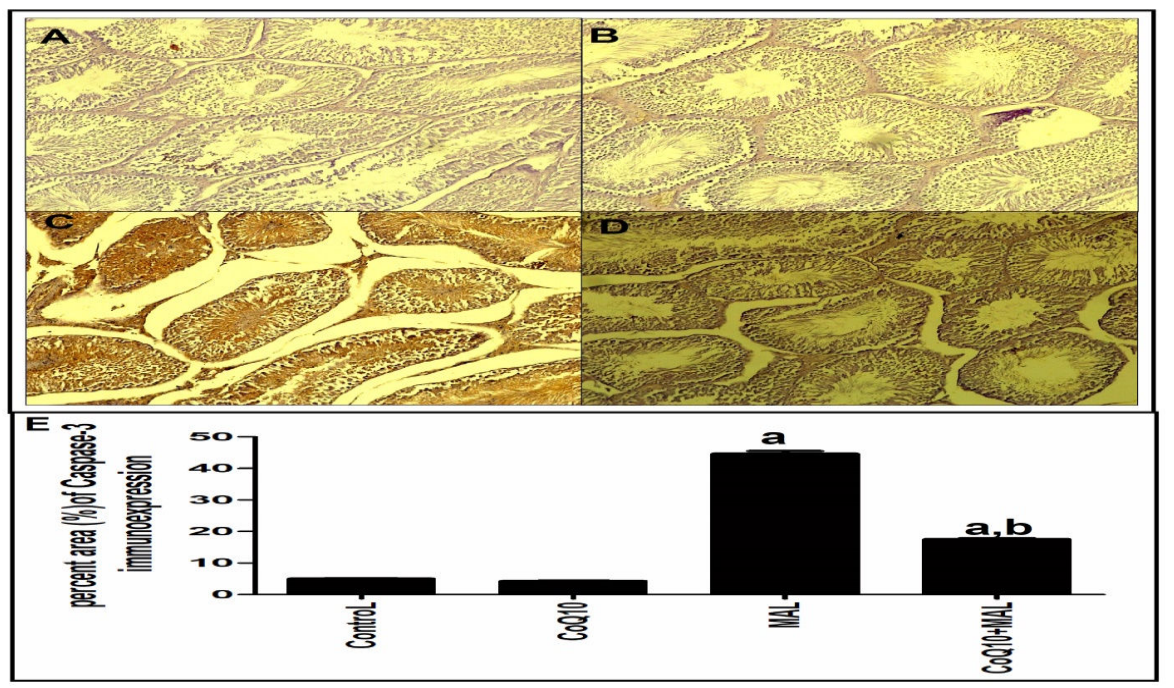

Fig.2: Effect of coenzyme (CoQ10, $10 \mathrm{mg} / \mathrm{kg})$ administration on the testes activity of malondialdehyde (MDA) (A), reduced glutathione (GSH)(B) and superoxide dismutase (SOD) (C) in rats exposed to Malathion (MAL $27 \mathrm{mg} / \mathrm{kg}$ ) induced toxicity. Values are represented as means $\pm \mathrm{SD}$. $(\mathrm{n}=6)$. Significant difference is reported when $\mathrm{P}<0.05$. Significant difference compared to control, ${ }^{b}$ significant difference compared to MAL.

3.4. Effect of CoQ10 on testicular apoptosis in MAL-treated rats at day 30. To evaluate cell death and the apoptotic cascade in the testicular tissue, the apoptotic markers (Bax and caspase 3) were evaluated in each of the various groups. Rats treated with MAL exhibited testicular cell loss as evidenced by the increased expression of Bax $(p<0.05)$ and Caspase $3(p<0.05)$ when compared to the control group, while concomitant treatment with CoQ10 was found to protect the testicular tissues by decreasing Bax and Casp3 expression (Figure $3 \& 4$ ). 


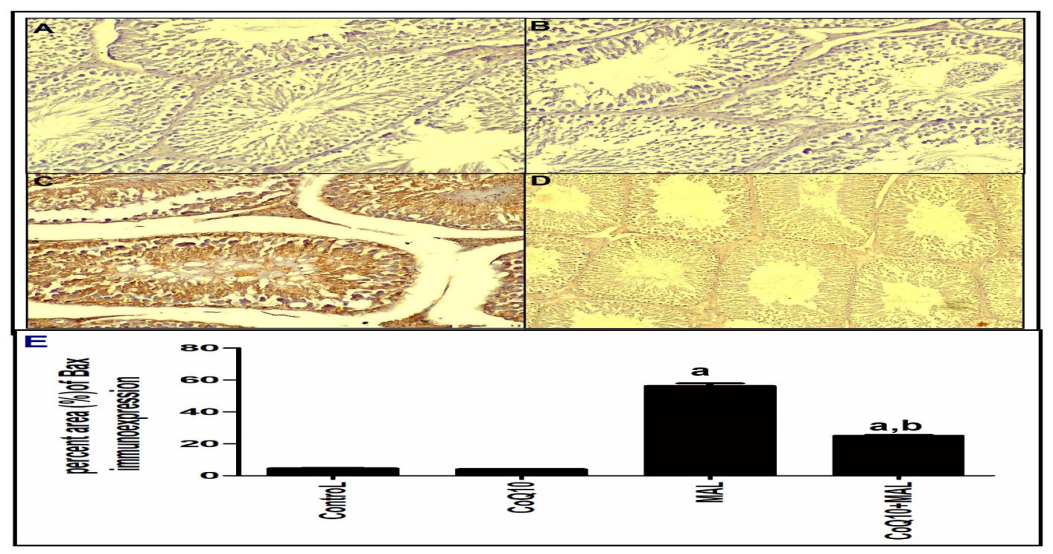

Fig.3: Effect of coenzyme (CoQ10, $10 \mathrm{mg} / \mathrm{kg})$ administration on the testes the caspase-3 expression in rats exposed to Malathion (MAL $27 \mathrm{mg} / \mathrm{kg}$ ) induced toxicity. Values are represented as means \pm SD. $(n=6)$. Significant difference is reported when $\mathbf{P}<0.05$. Significant difference compared to control, ${ }^{b}$ significant difference compared to MAL. Data was analyzed by one-way ANOVA using Tuckey's post hoc test

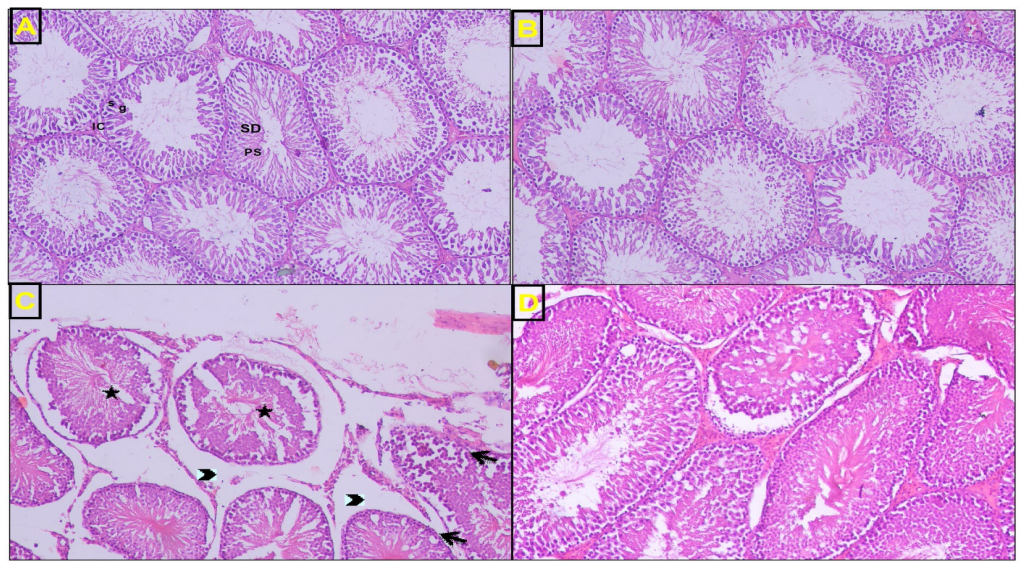

Fig.4: Effect of coenzyme (CoQ10, $10 \mathrm{mg} / \mathrm{kg}$ ) administration on the testes the BAX expression in rats exposed to Malathion (MAL $27 \mathrm{mg} / \mathrm{kg}$ ) induced toxicity. Values are represented as means means $\pm \mathrm{SD}$. $(\mathrm{n}=6)$. Significant difference is reported when $\mathbf{P}<$ 0.05. ${ }^{\text {a }}$ Significant difference compared to control, ${ }^{b}$ significant difference compared to MAL. Data was analyzed by one-way ANOVA using Tuckey's post hoc test 


\subsection{Effect of CoQ10 on testicular histopathology in MAL-treated rats}

Histological examination of the testes revealed that both control and CoQ10treated rat testes have normal structure, with ordinary seminiferous tubules, regular spermatogenesis and orderly maturation of germ cells (Fig. 4A and B, respectively). In both groups, from the periphery to the center of the lumen, spermatogonia, primary and secondary spermatocytes, spermatids, and spermatozoa appear normal with, plenty of sperms and were supported with cluster of peritubular myoid cells and Leydig cells. In contrast, MAL-treated group showed distortion of normal testicular architecture as evidenced by hypospermatogenesis, spermatogenic and Leydig cells degeneration, seminiferous tubules atrophy and widened interstitial space with severe vacuolization in interstitial tissues (Fig. 4 C). Co-treatment with CoQ10 resulted in amelioration of the toxic effects of MAL as revealed by the improvement in the morphology of the seminiferous tubules, abundance of normal spermatogenic cells and sperms and decreased necrotic cells in tubular lumens (Fig. 4 D)

\section{Discussion}

Pesticides are known to induce reproductive toxicity in animals and humans and many studies have documented the role of pesticides in mediating infertility ${ }^{(28,29)}$. Previous researches have reported that the male reproductive system have been affected by some OP insecticides including MAL which causes serious harmful effects on male reproductive system, and reduces male infertility ${ }^{(30,31,32)}$.

Sperm quality is an important indicator for fertilizing ability. It is a sensitive index to study the effect of a variety of physical and chemical factors to reproductive cells ${ }^{(33)}$. In this study, malathion induced testicular toxicity that was evident in terms of reduced testicular weight, sperm count and motility. The same finding was demonstrated in many researches ${ }^{(34,35,36,37)}$.

The weight of testes is largely dependent on the mass of differentiated spermatogenic cells. The reduced tubule size, decreased number of germ cells and elongated spermatids may lead to the reduction in the weight of testes as observed in this study ${ }^{(38)}$. 
We further confirmed these toxic effects by histological studies which revealed that malathion caused testicular lesions characterized by markedly severe widening of interstitial spaces and hypospermatogenesis. We also observed atrophic seminiferous tubules, disordered and decreased spermatogenic cells, increased degeneration, and sloughing of spermatogenic cells. This could indicate that malathion affect the testicular function seriously in rats in accordance with earlier reports ${ }^{(39,40)}$.

LH and FSH activities depend on both the quantity of these hormones and availability of their specific receptors in the testes. It was clarified that there is an adverse effect on testicular function on exposure to environmental pollutants mediated by lowering LH secretion by pituitary and steroidogenesis by Leydig cell ${ }^{(41,42,43)}$. By the end of the month of this study, the levels of LH and testosterone in the MAL treated group were significantly lower than their levels in control groups and the FSH is higher in the malathion-treated group. This is in line with the finding of Mahgoub and El-Medany and Ali and Ibrahim ${ }^{(44,45)}$. This may be made clear by the supposed antagonism of malathion to androgen receptor which subsequently change the glycosylation of gonadotrophins, and this leads to the inhibition of their levels ${ }^{(46)}$. On the other hand it was reported that production of gonadotropins was affected by malathion may be due to the interruption of the hypothalamic-pituitarytesticular axis ${ }^{(47)}$.

It is probable gonadotrophins and testosterones are key hormones, which regulate spermatogenesis. LH is secreted by the pituitary gland then induces Leydig cells to secrete testosterone. In consistence, malathion was described as an endocrine disruptor that decreased the reproductive performance that was confirmed by the resulting reduction of $\mathrm{LH}$ and the increased FSH level.

The ratio between endogenous oxidative and antioxidant molecules is, thus considered a critical determinant of cell fate. The present study confirmed that MAL increased the peroxidation product, MDA, while decreasing the mean levels of the protective antioxidant enzymes glutathione, GSH and superoxide dismutase, SOD in testicular tissue which considered as a critical part of homeostatic machinery in male gonads ${ }^{(48)}$. However, the major underlying mechanism of MAL and other OPs toxicity is oxidative stress that results from 
the generation of many free radicals, besides their ability to cross the bloodtestes barrier ${ }^{(49)}$, after which they induce oxidative stress, lipid peroxidation, correspondent depletion of antioxidant enzymes and disruption of the oxidantantioxidant scale favoring the oxidant limb with subsequent damage in the biological membranes in the testes. This in turn may cause the degeneration of the spermatogenic and Leydig cells, which disrupts spermatogenesis and reduces sperm counts ${ }^{(50,51)}$ probably due to the unique structure of the male germ cell membrane, which is rich in polyunsaturated fatty acids highly predisposed to lipid peroxidation $^{(52)}$.

Through free radical accumulation, MAL induces cellular stress, initiating a cascade of events, leading eventually to apoptosis ${ }^{(53,54)}$. Initially, proteolytic enzymes, called caspases, expressed as pro-enzymes are activated into mature caspases ${ }^{(55)}$. In the present study, MAL significantly increased caspase 3 expression levels in rat testes, as a marker of apoptosis. Caspase 3 is pivotally situated in both intrinsic and extrinsic receptor-mediated apoptotic pathways, as it is considered an effector or executioner caspase that regulates downstream caspase cascade system ${ }^{(56)}$. MAL can increase the rate of apoptosis in spermatogenic cells through increasing apoptosis-related proteins Bax that promotes apoptosis by depleting the growth factors ${ }^{(57)}$. This coincides with our results that clearly indicated the apoptotic effect of malathion by upregulation of Bax and caspase 3

MAL oxidative tendency logically suggested antioxidants as one of the therapeutic options to protect the testes. Consequently, previous studies with several compounds possessing antioxidant properties have been found to be effective in ameliorating MAL-induced testicular damage, including curcumin $^{(58)}$, vitamin $\mathrm{E}$ and selenium ${ }^{(59)}$. Current study demonstrates that the antioxidant CoQ10, administered concomitantly with MAL, reversed oxidative stress and apoptosis, as well as improved the gross and microscopic pictures of the testes. One of the advantages of CoQ10 over other antioxidants is that it is a naturally occurring endogenous antioxidant that has long been used as food supplementation $^{(60)}$. Other advantage of CoQ10 is possessing favorable effects specific to testes, where it is present in measurable concentrations that correlate with testicular functionality ${ }^{(61)}$. This effect was proved that in this study as the absolute and relative testicular weight was restored following CoQ10 
supplementation, while the testosterone, LH, and FSH levels were improved; signs of oxidative stress were decreased as evidenced by the reduction in MDA. In addition, CoQ10 enhanced expression and level of glutathione and the antioxidant enzymes SOD. Fouad et al. revealed that CoQ10 could suppress oxidative stress in the testes by inhibiting lipid peroxidation and enhancing antioxidant enzyme activity ${ }^{(62)}$. This in turn can counteract oxidative damage and sustain the function of Leydig cells protecting testosterone secretion ${ }^{(63)}$. The key application of CoQ10 in the testes is to increase the levels of CoQ10 and its reduced form, ubiquinol, in the semen ${ }^{(64)}$. Ubiquinol is a potent fatsoluble antioxidant that can regenerate other antioxidants including vitamins $\mathrm{E}$ and $\mathrm{C}^{(65)}$. It also eliminates peroxyl radicals resulting from the lipid peroxidation process ${ }^{(66)}$. The antiapoptotic effect of CoQ10 has been described by several studies ${ }^{(67,68)}$, and it was confirmed in this study when CoQ10 treatment downregulated the expression proapoptotic genes Casp3 and Bax. Papucci et al. attributed the antiapoptotic effect of CoQ10 to the inhibition of DNA fragmentation and mitochondrial depolarization as well as increasing ATP levels ${ }^{(69)}$. Additionally, CoQ10 inhibits nuclear translocation of apoptosisinducing factors and prevents cell death via the inhibition of mitochondrial complex I activity ${ }^{(70)}$.

\section{Conclusion}

The antioxidant and anti-apoptotic activities of coenzyme Q10 can be considered the main factors responsible for the testicular protective effect of coenzyme Q10 against MAL-induced acute testicular toxicity in rats. Therefore, coenzyme Q10 represents a potential protective candidate to ameliorate testicular injury and dysfunction induced by malathion exposure. 


\section{References}

1- Espinoza-Navarro O, Bustos-Obregón EA.Effects of Malathion on Cellularity and Sperm Differentiation in Testes and Epididymis of Adult Rats gency for toxic subtances and disease registry (ATSDR).Technical register for public health professionals..Int. J. Morphol. 2000; 32(1):119-124.

2- Bustos-Obregón E, Hartley BR. Ecotoxicology and testicular damage (Environmental chemical pollution). A review. Int. J.Morphol.2008;26(4):833-40.

3- Abolhassani M, Asadikaram G, Paydar P, Fallah H, Aghaee-Afshar M, Moazed V, Akbari H, Moghaddam SD, Moradi A. Organochlorine and organophosphorous pesticides may induce colorectal cancer; a case - control study. Ecotoxicology and Environmental Safety.2019;178, 168-177

4- Kumral A, Kumral NA, Gurbuz O. Chlorpyrifos and deltamethrin degradation potentials of two Lactobacillus plantarum strains. Türkiye Entomoloji Dergisi.2020;44(2):165-176

5- Thant ZL, Aye AT, Aung ZM, Mark GR, Wattasit S. Effects of pesticide exposure on reproductivity of male groundnut farmers in Kyauk Kan village, Nyaung-U, Mandalay region, Myanmar.Risk Manag Healthc Policy.2018;11:235-241.

6- Thein MT. Effects of pesticides on human health: a preliminary study with emphasis on male reproduction, Pyin Oo Lwin, Myanmar. Myanmar Health Sci Res J.2010;24(3):3-7.

7- Swan SH, Kruse RL, Liu F, Barr DB, Drobnis EZ, Redmon JB , Wang C, Brazil C, Overstreet JW,. Semen quality in relation to biomarkers of pesticide exposure. Environ Health Perspect. 2003;111(12):1478-1484.

8- Akinola OB, Biliaminu SA, Adedeji OG, Oluwaseun BS, Olawoyin OM, Adelabu TA. Combined effects of chronic hyperglycaemia and oral aluminium intoxication on testicular tissue and some male reproductive parameters in Wistar rats. Andrologia.2016;48(7):779-86.

9- Bolat G, Abaci S. Non-Enzymatic Electrochemical Sensing of Malathion Pesticide in Tomato and Apple Samples Based on Gold Nanoparticles-Chitosan-Ionic Liquid Hybrid Nanocomposite. Sensors (Basel, Switzerland). 2018;18(3):733. 
10- Badr AM. Organophosphate toxicity: updates of malathion potential toxic effects in mammals and potential treatments. Environmental Science and Pollution Research International. 2020;27(21):26036-57.

11- Mnif W, Hassine AI, Bouaziz A, Bartegi A, Thomas O, Roig B. Effect of Endocrine Disruptor Pesticides: A Review .Int J Environ Res Public Health. 2011 Jun; 8(6): 2265-2303.

12- Jiri Bajgar Laboratory diagnosis of organophosphates/nerve agent poisoning . Klinicka Biochemie a Metabolismus. 2005;13(1):40-47

13- Bayrami M, Hashemi T, Malekirad AA, Ashayeri H, Faraji F, Abdollahi M Electroencephalogram, cognitive state, psychological disorders, clinical symptom, and oxidative stress in horticulture farmers exposed to organophosphate pesticides. Toxicol Ind Health.2012; 28(1):90-96.

14- Contreras HR, Bustos-Obregón E. Morphological alterations in mouse testes by a single dose of malathion. J. Exp. Zool. 1999;284:355-359.

15- Uzun FG, Kalender S, Durak D, Demir F, Kalender Y. Malathion-induced testicular toxicity in male rats and the protective effect of vitamins $\mathrm{C}$ and $\mathrm{E}$. Food Chem. Toxicol.2009;47:1903-1908.

16- Prakash S, Sunitha J, Hans M. Role of coenzyme $Q_{10}$ as an antioxidant and bioenergizer in periodontal diseases. Indian J. Pharmacol. 2010;42:334.

17- Rodick TC, Seibels DR, Babu JR, Huggins KW, Ren G, Mathews ST. Potential role of coenzyme Q10 in health and disease conditions. Nutrition and Dietary Supplements.2018;10:1-11.

18- El-khadragy M, Al-Megrin W A, AlSadhan NA, Metwally DM, El-Hennamy RE, Salem FH, Kassab RB , Abdel Moneim AE. Impact of Coenzyme Q10 Administration on Lead Acetate-Induced Testicular Damage in Rats.Oxid Med Cell Longev. 2020; 4981386.

19- Balercia G, Buldreghini E, Vignini A, Tiano L, Paggi F, Amoroso S, RicciardoLamonica G, Boscaro M, Lenzi A, Littarru G. Coenzyme Q10 treatment in infertile men with idiopathic asthenozoospermia: a placebo-controlled, double-blind randomized trial. Fertil Steril. 2009;91(5):1785-92.

20- Ahmadi S, Bashiri R, Ghadiri-Anari A, Nadjarzadeh A. Antioxidant supplements and semen parameters: An evidence based review. Int J Reprod Biomed. 2016;14(12):729-736.

21- Silvestri S, Orlando P, Armeni T, Padella L, Brugè F, Seddaiu G, Littarru GP, Tiano L. Coenzyme Q10 and $\alpha$-lipoic acid: antioxidant and pro-oxidant effects in plasma 
and peripheral blood lymphocytes of supplemented subjects. J Clin Biochem Nutr. $2015 \mathrm{Jul} ; 57(1): 21-6$.

22- Quinn R. Comparing rat's to human's age: how old is my rat in people years? Nutrition. 2005 Jun;21(6):775-7.

23- Erol B, Bozlu M, Hanci V, Tokgoz H, Bektas S, Mungan G. Coenzyme Q10 treatment reduces lipid peroxidation, inducible and endothelial nitric oxide synthases, and germ cell-specific apoptosis in a rat model of testicular ischemia/reperfusion injury. Fertil Steril. 2010 Jan;93(1):280-2.

24- Uzun FG, op,cit

25- Espinoza-Navarro O, op,cit.

26- Côté A, Silva R, Cuello AC. Current protocols for light microscopy immunocytochemistry. In: Cuello, A.C. (Ed.),Immunohistochemistry II. John Wiley \& Sons, Chichester, 1993;147-168.

27- Ramos-Vara JA. Technical aspects of immunohistochemistry. Vet Pathol. 2005 Jul;42(4):405-26.

28- Mostafa AO, Abdel-Kader RM, Heikal OA. Enhancement of cognitive functions by rice bran extract in a neuroinflammatory mouse model via regulation of PPAR $\gamma$. Journal of Functional Foods. 2018;48:314-321.

29- Runkle, J., Flocks, J., Economos, J., Dunlop, A.L., 2017. A systematic review of Mancozeb as a reproductive and developmental hazard. Environ Int 99, $29-42$.

30- Hu Y, Ji L, Zhang Y, Shi R, Han W, Tse LA, Pan R, Wang Y, Ding G, Xu J, Zhang Q, Gao Y, Tian Y. Organophosphate and Pyrethroid Pesticide Exposures Measured before Conception and Associations with Time to Pregnancy in Chinese Couples Enrolled in the Shanghai Birth Cohort. Environ Health Perspect. 2018 Jul 9;126(7):077001.

31- Babu NS, Malik JK, Rao GS, Aggarwal M, Ranganathan V. Effects of subchronic malathion exposure on the pharmacokinetic disposition of pefloxacin. Environ Toxicol Pharmacol.2006;22(2):167-171.

32- Rattan S, Zhou C, Chiang C, Mahalingam S, Brehm E, Flaws JA. Exposure to endocrine disruptors during adulthood: consequences for female fertility. J. Endocrinol.2017;233:109-129.

33- Adhikary P, Banerji J, Chowdhury D, et al. Antifertility effect of Piper betle Linn. extract on ovary and testes of albino rats. Indian Journal of Experimental Biology. 1989 Oct;27(10):868-870. 
34- Geng X, Shao H, Zhang Z, Ng JC, Peng C. Malathion-induced testicular toxicity is associated with spermatogenic apoptosis and alterations in testicular enzymes and hormone levels in male Wistar rats. Environ Toxicol Pharmacol. 2015 Mar;39(2):659-67.

35- Mahrous AI, Farooq AW, Athar MK, Mina TK, Marwa M. Anwar Ashokkumar Thirunavukkarasu, Mohammed U. Sayeed. Protective effects of selenium on malathion-induced testiculartoxicity in mice Indian Journal of Animal Research.2020; 54( 3): 335-341.

36- Choudhary N, Goyal R, Joshi SC.Effect of malathion on reproductive system of male rats. J Environ Biol.2008;29:259-262

37- Slimen S, Saloua GNEF.Oxidative stress and cytotoxic potential of anticholinesterase insecticide, malathion in reproductive toxicology of male adolescent mice after acute exposure. Iran J Basic Med Sci.2014;17(7):522

38- Chiou TJ, Chu ST, Tzeng WF, Huang YC, Liao CJ. Arsenic trioxide impairs spermatogenesis via reducing gene expression levels in testosterone synthesis pathway. Chem Res Toxicol. 2008;21: 1562-1569.

39- Sobarzo C, Bustos-Obregon E. Acute effect of Parathion on the seminiferous epithelium of immature mice. Rev. Chil. Anat. 2000;18:1.

40- Geng X, op,cit.

41- Magnusson U, Ljungvall K. Environmental pollutants and dysregulation of male puberty - a comparison among species. Reprod Toxicol.2014;44:23-32.

42- Ali RI, op,cit.

43- Mahrous A. Ibrahim, Farooq A. Wani, Athar M. Khalifa, Mina T. Kelleni, Marwa M. Anwar, Ashokkumar Thirunavukkarasu and Mohammed U. Sayeed Protective effects of selenium on malathion-induced testicular toxicity in mice.Indian Journal Of Animal Research.2020;(54):335-341

44- Mahgoub AA, El-Medany AH Evaluation of chronic exposure of the male rat reproductive system to the insecticide methomyl. Pharmacol Res.2001;44(2):73-80.

45- Ali RI, Ibrahim MA. Malathion induced testicular toxicity and oxidative damage in male mice: the protective effect of curcumin. Egypt J Forensic Sci.2018;8:70

46- Sikka SC, Naz RKEndocrine disruptors and male infertility. In: Naz RK (ed) Endocrine disruptors: effects on male and female reproductive systems. CRC Press, Boca Raton, Florida, 1999;225-246. 
47- Roohbakhsh A, Moghaddam AH, Delfan KM. Anxiolytic-like effect of testosterone in male rats: GABAC receptors are not involved. Iran $\mathrm{J}$ Basic Med Sci. 2011;14:376-382

48- Bedwal S, Prasad S, Nair N, Saini MR, Bedwal RS.Catalase in testes and epididymidis of wistar rats fed zincdeficient diet. Indian J. Pharm. Sci. 2009;71, 5558.

49- Kidd H, James DR. The agrochemicals handbook. 3rd ed. Cambridge, UK: Royal Society of Chemistry Information Services; 1991.

50- Pearson JN, Patel M The role of oxidative stress in organophosphate and nerve agent toxicity. Ann N Y Acad Sci.2016;1378(1):17-24.

51- Koltuksuz U, Irmak MK, Karaman A, Uz E, Var A, Özyurt H, Akyol Ö.Testicular nitric oxide levels after unilateral testicular torsion/detorsion in rats pretreated with caffeic acid phenethyl ester. Urol Res.2000;28(6):360-363

52- Lenzi A, Lombardo F, Sgro Pet al. Use of carnitine therapyin selected cases of male factor infertility: a double-blindcrossover trial.Fertility and Sterility. 2003;79:292300.

53- Penna-Videau S, Bustos-Obregn E, Cermeo-Vivas J R. Malathion affects spermatogenic proliferation in mouse. Int J Morphol. 2012;30: 1399-1407

54- Aboul-Soud MA, op,cit.

55- Kuribayashi K, Mayes PA, El-Deiry WS. What are caspases 3 and 7 doing upstream of the mitochondria? CancerBiol. Ther.2006;5, 763-765.

56- Tait SW, Green DR. Mitochondria and cell death: outermembrane permeabilization and beyond. Nat. Rev. Mol. CellBiol.2010;11, 621-632.

57- Youle RJ, Strasser A. The BCL-2 protein family: opposingactivities that mediate cell death. Nat. Rev. Mol. Cell Biol.2008;9,47-59.

58- Ali RI, op,cit.

59- Aboul-Soud MA, Al-Othman AM, El-Desoky GE, Al-Othman ZA, Yusuf K, Ahmad $\mathrm{J}$, Al-Khedhairy AA. Hepatoprotective effects of vitamin E/selenium against malathion-induced injuries on the antioxidant status and apoptosis-related gene expression in rats. J Toxicol Sci. 2011;36:285-96.

60- Bonakda RA, Guarneri E. Coenzyme Q10. Am. Fam.Physician 2005;72, 10651070.

61- Balercia G, Mancini A, Paggi F, Tiano L, Pontecorvi A,Boscaro M, Lenzi A, Littarru GP. Coenzyme Q10 andmale infertility. J. Endocrinol. Invest. 2009;32, 626632. 
62- Fouad AA, Al-Sultan AI, Yacoubi MT. Coenzyme Q10 counteracts testicular injury induced by sodium arsenite in rats. Eur J Pharmacol. 2011 Mar 25;655(1-3):91-8.

63- Palmeira CM, Santos DL, Seiça R, Moreno AJ, Santos MS. Enhanced mitochondrial testicular antioxidant capacity in Goto-Kakizaki diabetic rats: role of coenzyme Q. Am J Physiol Cell Physiol. 2001 Sep;281(3):C1023-8.

64- Balercia G, Mosca F, Mantero F, Boscaro M, Mancini A, Ricciardo-Lamonica G, Littarru G. Coenzyme Q(10) supplementation in infertile men with idiopathic asthenozoospermia: an open, uncontrolled pilot study. Fertil Steril. 2004 Jan;81(1):93-8

65- Turunen M, Olsson J, Dallner G. Metabolism and function of coenzyme Q. Biochim Biophys Acta. 2004 Jan 28;1660(1-2):171-99.

66- Potgieter M, Pretorius E, Pepper MS. Primary and secondary coenzyme Q10 deficiency: the role of therapeutic supplementation. Nutr Rev. 2013 Mar;71(3):1808.

67- El-Sheikh AA, Morsy MA, Mahmoud MM, Rifaai RA, Abdelrahman AM. Effect of coenzyme-q10 on Doxorubicin-induced nephrotoxicity in rats. Adv Pharmacol Sci. 2012;2012:981461.

68- Al Olayan EM, Aloufi AS, AlAmri OD, El-Habit OH, Abdel Moneim AE. Protocatechuic acid mitigates cadmium-induced neurotoxicity in rats: Role of oxidative stress, inflammation and apoptosis. Sci Total Environ. 2020 Jun 25;723:137969.

69- Papucci L, Schiavone N, Witort E, Donnini M, Lapucci A, Tempestini A, Formigli L, Zecchi-Orlandini S, Orlandini G, Carella G, Brancato R, Capaccioli S. Coenzyme q10 prevents apoptosis by inhibiting mitochondrial depolarization independently of its free radical scavenging property. J Biol Chem. 2003 Jul 25;278(30):28220-8.

70- Li H, Chen G, Ma W, Li PA. Water-soluble coenzyme q10 inhibits nuclear translocation of apoptosis inducing factor and cell death caused by mitochondrial complex I inhibition. Int J Mol Sci. 2014 Jul 31;15(8):13388-400. 


\section{الآثار الوقائية المتمبلة لمادة كيو • ا على سمية الخصية \\ التى يسببدها الملاثيون فى ذكور الجرذان \\ مزوة مدحت}

يعد مبيد المالاثيون من المبيدات العضوية الموجودة بكثرة فى البيئة المحيطة مما بسبب خللًا وظيفًِاً

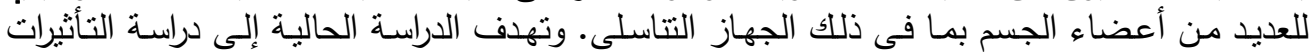

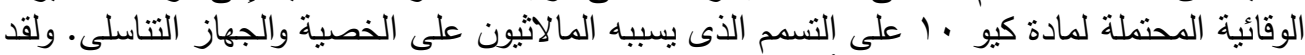

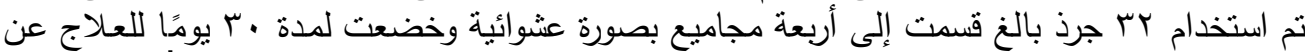

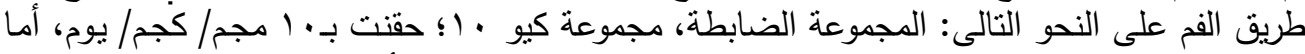

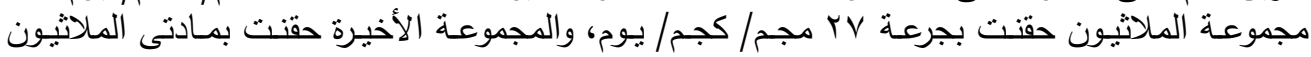
والكيو · ل معًا بالجرعات السابقة نفسها.

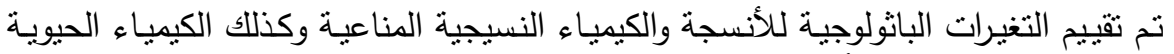

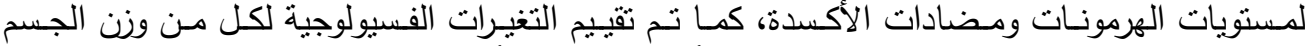

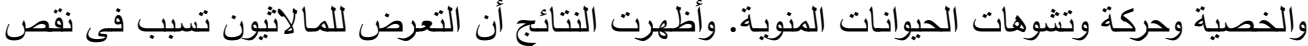

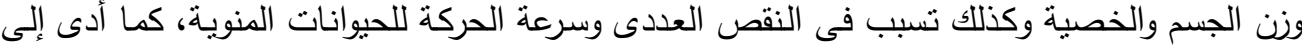

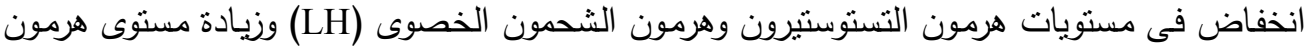

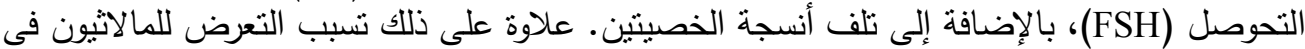

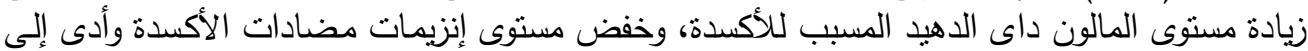

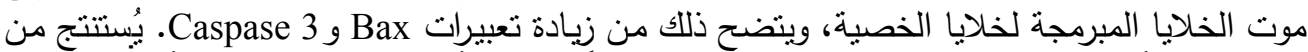

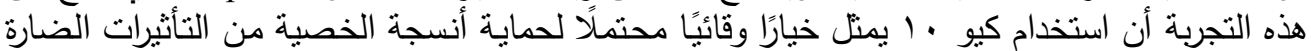

